\section{Diretrizes para a política de saúde de um governo popular e democrático*}

\author{
Luiz Salvador de Miranda Sá Junior *
}

\section{INTRODUÇĀO}

A ditadura militar, imperante no Brasil, nas duas últimas décadas, pode ser designada, sinteticamente, de antipopular, pois, dirigida para a exploração desmedida de imenso contingente populacional, favorecendo às chamadas elites representadas por infima parcela da população; de antidemocrática, porque divorciada da vontade da maioria e de antinacional, posto que, promoveu dependência e a desenfreada exploração do povo brasileiro, por empresas e bancos in ternacionais. À margem disto, generalizou-se a mais descarada corrupção. A sem-cerimônia com o interesse coletivo e com a opinião pública tornou fora de moda até a menor preocupação com a aparência de honestidade e de eficiência, na gestão do governo.

Este processo político-administrativo resultou, diversamente, em setores diferentes da vida nacional. Houve inegável incremento da economia. Mas a custo de não menos inegável involução das condiçðes de vida e de bem-estar social.

O setor saúde terá sido, talvez, o mais prejudicado, dentre aqueles que compõem as agências públicas de promoção do bem-estar, no país. A involução sanitária do Brasil é um fato incontestável, representando-se pelo incremento de doenças evitáveis e pelo ressurgimento daquelas que já haviam sido banidas do cenário nosológico nacional. Mais de metade de nossa população padece e paga seu tributo à desnutrição; a malária, a tuberculose, a doença de Chagas, a esquistossomose, a hanseníase, as gratroenterites, as doenças venéreas e todo o cortejo de doenças da pobreza apresentam índices crescentes. Recrudescem a febre amarela e a filariose. A par disso, crescem, também, aquelas patologias típicas dos países ricos: a obesidade, a arteriosclerose, as neoplasias, o diabetes, as cardiopatias. A incidência de AIDS se acelera, dobrando-se o número de casos novos, a cada dez meses, não sendo incrível que aí conquistemos um campeonato mundial. As doenças mentais são a segunda causa de invalidez e de benefícios previdenciários, acometendo a mais de dez, em cada cem brasileiros e, ainda assim, diz-se, inteligentemente, que não se constituem em proble. ma de saúde pública. .

Cadernos de Saúde Pública, R.J., 3 (3): 315-331, jul/set, 1987
* Conferência realizada em janeiro de 1987, para profissionais da área de Saúde Pública, em Recife. $P E$.

\author{
**Presidente da Associação Brasi. \\ leira de Psiquiatria.
}


A desimportância do setor saúde, na administração pública, pode ser aferida, seguramente, por três in dicadores infalíveis, dentre outros, naturalmente: a maior ou menor facilidade com que o governante o utiliza como instrumento de barganha; o percentual orçamentário que lhe é atribuído e, efetivamente, liberado e o grau de organização do setor. Compare-se o setor saúde com o de obras públicas, com o aparelho arrecadador e com o repressivo.

A recuperação do setor saúde e sua transformação em instrumento capaz de atender às necessidades da população, como um todo, constituem-se em compromisso de todas as forças políticas que se organizaram e cresceram no combate à ditadura militar, inclusive porque ela sucateou o aparelho sanitário e promoveu a insalubridade, contribuindo com a insatisfação popular e ampliando a oposição.

Daí, a necessidade de um diagnóstico sumário dos problemas, da ereção de princípios nor teadores da ação e da implementação de propostas que convirjam para o resgate desta fração da "dívida social", contraída para o povo brasileiro.

\section{DIAGNÓSTICO SUMÁRIO}

A ampliação e o aperfeiçoamento dos serviços de promoção da saúde e de prevenção das condições patológicas e a melhoria das condições de saúde, bem como, as de educação, cultura, moradia e transporte, têm sido a tônica das promessas de todos os políticos, em períodos pré-eleitorais. A despeito disto, as condições sanitárias da população estão cada vez piores e o sistema de assistência está arruinado e desacreditado.

2.1. Fatores que determinaram a involução das condições de saúde do povo brasileiro:

2.1.1. política econômica voltada para o privilegiamento do capital, em detrimento do trabalho, acentuando. se o processo de exploração, tanto no in terior da sociedade brasileira, quanto na ampliação do processo de exploração do país, por grupos financeiros estrangeiros;

2.1.2. deterioração das condições de trabalho, moradia, transporte, alimentação e lazer;

2.1.3. perda do poder aquisitivo da população assalariada, determinando a piora da nutrição e das condiçaes de higiene;

2.1.4. notória impunidade de atos desonestos e de violência, tornados modelos de comportamen to público;

2.1.5. decrescimento progressivo dos recursos financeiros destinados aos programas de bem-estar social; 
2.1.6. desleixo, pela administração pública direta, em favor das empresas públicas, nas quais o sistema de controle favorece desvios e má utilização de recursos.

2.1.7. degradação do sistema de instrução, notadamente, daquele destinado a preparar recursos humanos para a saúde.

2.2. Fatores que condicionam a baixa qualidade dos serviços de promoção de saúde e de prevenção da ocorrência, evolução ou da invalidez.

Os fatores que se reúnem para condicionar a baixa qualidade e o conseqüente descrédito dos serviços sanitários são de naturezas variadas e se apresentam, com diferentes intensidades, em cada caso. 0 trabalho de esquematizá-los e sistematizá-los, se, de um lado, resulta artificioso, tendente à supersimplificação e à mecanização, doutro, permite uma visão global do problema enfocado, que é o que se pretende aqui. Tais fatores podem ser ordenados em dois grupos: os ideológicos e os político-administrativos.

2.2.1. Fatores ideológicos:

a) $\mathrm{O}$ conceito de saúde

A primeira controvérsia ideológica, acerca do conceito de saúde, versa sobre se a saúde é algo natural ou sobrenatural. As concepções de mundo, animatistas, animistas e religiosas têm como denominador comum a crença de que a saúde de alguém é algo que depende, exclusivamente, de fenômenos que se processam fora e além da natureza, dos es. píritos ou da divindade. Foi pelo século IV, antes de nossa era, que o aparecimento do conceito de physis fundamentou e se fez essência de toda medicina, a partir de então, dando origem ao conceito de saúde como algo natural, resultado da interação dinâmica de fenômenos físicos, quími$\cos$, biológicos, psicológicos e sociais. A conceituação científica de saúde, como de resto a concepção científica de qualquer outra dimensão da natureza, é um dado fundamental da educação geral e da educação para a saúde, em particular.

A segunda controvérsia importante sobre a conceituação de saúde é posta na contradição en tre a compreensão da saúde, como um bem individual ou um bem coletivo. $O$ entendimento da saúde, como um atributo que interessava, somente, ao indivíduo que a gozava ou a perdia, foi fruto da crença em seu caráter mágico-sobrenatural. O conhecimento dos mecanismos de contágio e o avanço no entendimento sobre as doenças transmissíveis e sobre a dinâmica social puseram, em xeque, esta crença. A medicina islâmica medieval, com sua concepção orgânica e biologizada de sociedade, já defendia que a saúde (ou doença) de um, interessa a toCadernos de Saúde Pública, R.J., 3 (3): 315-331, jul/set, 1987 
dos; o que foi reforçado pelo conhecimento de que se alguém é hipodesenvolvido, inválido ou enfermo, produz menos ou nada e consome mais ou tem mais necessidade, contribuindo para diminuir a produção de bens e serviços e aumentar o consumo.

A terceira controvérsia se refere à divergência de opiniōes se a saúde é ou não, direito inerente à cidadania, mas, como esta divergência apresenta um conteúdo que se mescla e depende da conceituação de estado, será posta adiante.

Quarta divergência, e a mais importante, no que se refere ao conceito de saúde, é aquela que antepõe duas opiniōes acerca da própria essência do fenòmeno saúde: a) uma negativa (porque fundamentada em uma negação), tradicional e influenciada pela visão dualista, sobrenaturalista e individualista e que define saúde como ausência de sofrimento, enfermidade ou invalidez; b) outra, fundada na concepção natural, relaciona a sanidade com o estado de relativa satisfação das necessidades elementares e com a aptidão a se ajustar a novas circunstâncias de existência. Dar que, ao menos em teoria, hoje, quase todos definem saúde como bemestar físico, mental e social, vincando a natureza tridimensional do homem integral, unidade inseparável de suas dimensões biológicas, psicológicas e sociais. Tal conceituação pode ser criticada por seu caráter impreciso e tendente ao utópico. Impreciso, por que se inicia no conceito de bemestar como estado de satisfação das necessidades e, ainda, que se possa elencar um conjunto de necessidades como elementares (trabalho, moradia, transporte, vestuário, saúde, educação, lazer, cultura, justiça, etc.), a consciência de tais necessidades se dá de forma relativa, gerando aspiraçðes e expectativas decorrentes do conhecimento, das experiências anteriores e da comparação com outras pessoas ou grupos. Utópico, porque o ser humano tem necessidades, extremamente, plásticas e enorme potencial para criar outras necessidades, a partir da satisfação daquel as que o motivaram, an. teriormente; o homem é um animal insatisfeito, o que, provavelmente, é um dos mais importantes fatores que condicionam seu enorme potencial evolutivo e sua capacidade de transformar as condiçōes de vida e a natureza. E, modificando-as, gerar as premissas para sua própria transformação.

Implicaçōes médico-sociais das diferentes opiniōes acerca da saúde

A conceituação científica de saúde, como ocorrência natural, se antagoniza como explicação sobrenatural. $O$ profissional de saúde tem o dever de pugnar pela difusão de informações, cientificamente, confiáveis, embora deva fazê-lo, mantendo uma atitude permanente de respeito pela pessoa 
que alimenta superstiçoes, pois, que delas necessita. $O$ que parece inadmissível é considerar as práticas supersticiosas e, por isto mesmo, alienantes como altemativas às práticas científicas. $O$ pessoal sanitário serve à anti-saúde, quando se põe a serviço da superstição.

$\mathrm{O}$ individualismo, gerado pelas práticas econômicas baseadas na exploração de umas pessoas por outras (escravagismo, feudalismo, capitalismo) e que impregnou todas as suas manifestações sócio-culturais, produziu sempre a tendência a considerar a saúde dos homens, como atributo individual, interessando, exclusivamente, a quem experimentava saúde ou sofria doença. $O$ que foi muito reforçado pela concepção dualista de saúde e de doença, como atributos opostos e incomunicáveis. Aqui, o maniqueísmo se apresenta na ênfase, na doença ou no doente - "não existem doenças, mas doentes", sendo que as duas assertivas são falsas. Pois, existem doenças e existem doentes, sendo saúde e doença pólos conceituais, apenas, aparentemente, opostos de uma única totalidade, inexistindo um, sem o outro.

A superação do individualismo, no estudo da teoria e da prática sanitária, resultou do desenvolvimento do modo de produção capitalista que obrigou à concentração dos tra. balhadores, em um único local, ao crescimento urbano e à necessidade de qualificar a mão-de-obra para operar a tecnologia produtiva mais sofisticada; quando, então, se difundiu o conhecimento de que as doenças dos pobres ameaçavam os ricos e que a má condição de saúde dos operários comprometia a produtividade e, conseqüentemente, diminuía o lucro. A saúde pública, como instituição govemamental, as práticas de higiene e os procedimentos preventivos, se generalizaram neste momento. Nasceram da necessidade da classe dominante, da idéia do homem, como máquina humana, como instrumento de produzir e não de qualquer pretensão humanista; embora fosse humanista, grande parte dos profissionais se dedicaram e se dedicam à sua implementação e desenvolvimento, desde que, para eles, se abriu o necessário espaço institucional.

\section{b) A saúde e o poder estatal}

O estado é a mais ampla e abragente de todas as instituiçőes. Enquanto instituição, o estado é uma rede de funções e de papéis que se constituem na essência da organização social. A propriedade privada, a exploração do trabalho humano e o surgimento das classes sociais geraram a necessidade da elaboração de um sistema de normas e valores, de instrumentos ideológicos e políticos para justificar a existência do poder,como instrumento de coerção,para legitimá-loe perpetuá-lo. Explica-se a existência do estado e das demais Cadernos de Saúde Pública, R.J., 3 (3): 315-331, jul/set, 1987 
instituições abrangidas por ele, pela necessidade natural que têm as organizações sociais de modular as relações, entre suas partes componentes e de controlar o exercício do poder.

O poder estatal nasceu para perpetuar o sistema de exploração e intermediar as contradições existentes na intimidade da classe dominante. Ȧ medida que a atuação polí. tica dos segmentos sociais explorados foi se tomando mais influente, transformou-se o objetivo manifesto da existência do estado liberal, o qual passou a pretender tornar-se intermediário e árbitro das relações sociais todas, inclusive as contradições que opõem exploradores e explorados.

$\mathrm{Um}$ dos fatores que mais estimulam e promovem a consciência, a motivação e a mobilização das camadas populares, no sentido da transformação do poder estatal, tem sido a consciência de seu direito ao bem-estar expresso por sua participação, no consumo dos bens e dos serviços produzidos por todos. A essência da democracia se reflete no grau de participação de todos, no fruto do trabalho comum. Tudo o mais é formalidade.

Os estados modernos são unitários ou federativos. Nos primeiros, o poder central nacional designa todas as demais instâncias regionais ou locais de poder que a ele se subordinam. Nas federações podem ocorrer numerosos graus de "federatividade", a qual se expressa pela autonomia que cada unidade federada goza, em relação às demais e ao poder central.

O governo se constitui dos instrumentos político-administrativos incumbidos da gerência do poder estatal. É nele que se concentra, concretamente, nas instâncias federal, estadual e municipal do estado, todo o instrumental do poder. As instituições governamentais do estado, que incluem os partidos políticos, se opõem mais ou menos, agudamente, à sociedade civil, composta pelas instituições e organizações sociais, também in tegrantes do estado, mas não governamentais, não estando, formalmente, hierarquizadas nem subordinadas às instituições e organizações do govemo. Os sindicatos, sociedades e associações civis são organizações da sociedade civil e nunca devem ser confundidas ou se de xarem confundir com as organizaçōes e as instâncias do governo, sob pena de sacrificarem o que é essencial à sua existência.

Implicações médico-sociais destas questões

$O$ estado como agência de bem-estar. $O$ estado moderno assume a responsabilidade de promover a segurança $e$ bem-estar do cidadão. É característica essencial do estado que exista uma correspondência necessária entre seus direitos e deveres e os direitos e os deveres da cidadania. Tudo o 
que é direito do estado, como por exemplo, cobrar impostos, corresponde a um dever do cidadão, o dever de pagálos. E se saúde é bem-estar, sendo o bem-estar da cidadania um direito, corresponde-se-lhe o dever do estado de garantir este direito.

O caráter da forma e do conteúdo do estado. Não é sempre que uma mudança na forma do estado ou na maneira pela qual ele é governado, corresponde a uma mudança em seu conteúdo. Muitas vezes, "plus ça change, plus c'est la même chose", contudo, é possivel, mesmo em formas muito atrasadas de estado, uma ação política transformadora, no sentido de que sejam aperfeiçoados os instrumentos políticos e legais de participação, não, apenas, no exercício das formalidades da democracia, mas na transformação dos mecanismos definidores e reguladores das relações econômicas. $\mathrm{O}$ aperfeiçoamento da política de bem-estar e, conseqüentemente, da política de saúde é premissa e resultado desta transformação. Para que tais mudanças sejam significativas, é essencial que se reforce e se amplie o conteúdo democrático do estado brasileiro. Não basta a superação da ditadura militar, enquanto forma de governo; pois é preciso transformar o próprio con teúdo do estado, tornando-o mais popular. $O$ que implica, inclusive, em multiplicar, ampliar e aperfeiçoar o sistema de saúde a serviço da população. Sem esquecer que, embora o quadro politico atual de mudança tenha sido motivado pelos movimentos populares, pelas manifestações eleitorais, sobretudo a partir de 1974 e se tenha dado, a partir de uma estratégia de ampliação da frente politica de oposição, grande parte de tais mudanças está confiada aos mesmos agentes sociais e institucionais que impuseram a ditadura, exerceram-na e dela se beneficiaram. A cada momento, a dinâmica da realidade mutável impõe um sistema de alianças, que deve ser diferente do anterior. A luta política pela Reforma Sanitária se dá neste contexto. Não queremos mudar, apenas, a forma da assistência pública, queremos transformar o conteúdo do estado, inclusive, no que diz respeito à sua função de promotor de bem-estar e de saúde. Porque a Reforma Sanitária transcende de muito, os limites das instituiçōes e organizações de saúde, dependendo da definição constitucional acerca da forma e da natureza da propriedade, das relaçðes de trabalho e da organização política.

Surgem, daí, no cenário político, duas posições, aparentemente, opostas: os que pretendem que as mudanças institucionais da área da saúde promove, por si só, a transformação da natureza do estado e os que afirmam que, apenas, o estado socialista poderá ser um garantidor efe tivo do bem-estar da população, resultado inútil, todo esforço de aperfeiçoamento da instituição sanitária, enquánto vigir o

Cadernos de Saúde Pública, R.J., 3 (3): 315-331, jul/set, 1987 
sistema capitalista. 0 voluntarismo e o reformismo da primeira e o nihilismo da segunda posição são, identicamente, equivocados. Saúde não é, somente, bem-estar, saúde é luta. A luta política pelo aperfeiçoamento das condições de sanj. dade e de prevenção, além de melhorar a saúde do povo, é importante fator de motivação e de mobilização do processo político de organização da sociedade e de influência na gestão do poder público. Quanto maior e mais enraizada for a consciência da população de que saúde é bem-estar e que o bem-estar é decorrência da satisfação de necessidades básicas do indivíduo e de proteção do ambiente, estando, inseparavelmente, interligada à educação, à habitação, aos transportes, ao vestuário, à higiene do ambiente, à política salarial e a outras necessidades individuais e sociais, tanto mais a sanidade e o sistema de saúde serão obje to de reivindicações e de propostas políticas concretizáveis.

A participação das associações profissionais, dos sindi. catos e do corpo técnico das organizações e agências de saú. de na administração dos serviços.

A eleição dos dirigentes sanitários, pelos técnicos e demais funcionários do setor, tem sido posta como aspiração muito difundida, na área da saúde. Parece, politicamen. te, incorreta porque: 1. pretende que os funcionários, e não os usuários, sejam os únicos ou maiores interessados na ação do serviço; 2 . viola o princípio da autonomia dos organismos da sociedade civil, em relação ao governo; 3 . ignora a responsabilidade que o govemante, democraticamente, escolhido, tem com relação à atividade de seus subordinados e elimina a competência do governante de escolher sua equipe, facilitando a desorganização do sistema; 4 . favorece a constituição de grupos internos que dirigem a atividade do serviço, em função de interesses individuais ou corporativistas. Um único argumento, socialmente, aceitável apóia esta proposta: é menos mau que o dirigente seja escolhido por eleição, entre os funcionários, que, como acontece quando se faz o loteamento do governo, indicado por um cabo eleitoral, interessado apenas em manter sua clientela ou por político inescrupuloso e corrupto.

A melhor posição é a da organização de conselhos de usuários e servidores, com preponderância dos primeiros para fazer a profilaxia do corporativismo, que possa até destituir o dirigente incapaz ou incorrigivel, pelos meios ao seu alcance. Mas a responsabilidade de nomear deve ser atributo do governante. A legitimidade da escolha se assenta na própria legitimidade da eleição do governante para governar.

A necessidade de unificação do sistema de saúde e o caráter federal do estado brasileiro

Ao longo dos vinte anos da ditadura, a federação bra- 
sileira foi ficando um mito cada vez maior. De fato, o estado brasileiro vem funcionando como estado unitário, embora se mantivessem intactos os mecanismos formais de autonomia das unidades federadas. Fazia-se de conta que era uma federação, assim como se fazia de conta que o país era uma democracia. Por força da legislação centralizadora, do controle do aparelho repressor e, principalmente, pela centralização dos tributos e da arrecadação previdenciária, a união era, realmente, quase o único poder. Durante esse período o Ministério da Saúde e o da doença, o Ministério da Previdência Social, controlaram quase todos os instrumentos e recursos para a saúde, ainda que estes pertencessem e fossem administra dos pelos estados, municipios ou particulares. $\mathrm{Na}$ prática, os governos municipais vêm funcionando como se fossem sucursais do poder estadual e, este, como filial do poder federal. Esta situação, somente, poderá ser revertida a partir da Reforma Tributária e da clara definição das atribuiçōes da união, dos estados e municípios, com relação ao setor saúde. As propostas de unificação do sistema de saúde, seja por delegação ou transferència de atribuiçōes para os estados e municípios, serão meras manobras demagógicas, exercício de voluntarismo ou sobrecarga indevida de responsabilidade para as unidades estaduais e municipais, enquanto, à união, se atribuir uma cota, desmedidamente, grande da carga tributária e a totalidade da arrecadação previdenciária. E, absolutamente, fundamental que se defina, com a maior precisão possivel, a área de competência a responsabilidade de cada instância do poder estatal no que diz respeito às ações de saúde e que a esta competência corresponda fração proporcional dos recursos arrecadados.

Qualquer que seja a opção que se fizer pela divisão do trabalho sanitário, não é crível que, ao poder federal, não sejam atribuídas algumas atividades, quer por causa da necessária unificação nacional de algumas delas, quer pelos graus muito diferentes de organização e competência dos serviços de saúde das unidades federadas.

Outro fato que não pode ser desprezado é que muitas das propostas de reforma da organização sanitária, no Brasil, são cópias da organização sanitária de estados socialistas, quase todos eles estados unitários, sendo muito difícil a transposição, não fora por outras razões mais significativas, pela diferença da estruturação do poder estatal.

Outra implicação médico-social importante deste tema diz respeito à atividade dos funcionários públicos. Tradicionalmente, os governos se pretendem credores da lealdade dos funcionários. E não o são. $\mathrm{O}$ credor principal da lealdade dos funcionários, mesmo daqueles que exercem cargos de confiança dos governantes, é o povo. O serviço público 
deve existir para servir ao povo e atender aos seus interesses. A atitude de compromissos para com a população usuária é algo que faz muita falta no serviço de saúde e deve ser objeto de incansável combate ideológico, por parte dos militantes de partidos populares. Os comportamentos funcionais incompetentes, omissos ou desonestos, às vezes, são baseados na afirmação de quanto pior, melhor ou na inutilidade de tentar melhorar o serviço público. Mas estas são vãs justificativas para encobrir comportamentos anti-sociais e egoístas. Um político democrata e popular, qualquer que seja o seu grau de responsbilidade no governo do seu partido, ou naquele aliado, no qual ele participe, pois se deve presumir que não será funcionário de confiança de adversários, tem o dever de ensinar com seu exemplo e fixar a ima. gem de probidade e eficiência, a serviço do interesse da populaçđo, mesmo que, no momento, pareça prejudicar, eleitoralmente, ao seu govemo; após, será vantajoso.

c) Relação entre as práticas curativas e preventivas

A dissociação conceitual de prevenção e assistência, saúde e doença, higiene e medicina, procedimentos preventivos e curativos e outras que tais traduzem um descaminho ideológico de cunho dualista ou mecanicista. A dicotomização das práticas sanitárias preventivas e curativas, realizadas até hoje, foi um dos fatores mais importantes pela inoperância e ineficiência de nosso sistema sanitário. $O$ conceito mo. derno de prevenção abrange as práticas de prevenção primária (promoção do bemestar e profilaxia da ocorrência de enfermidades), secundária (prevenção da evoluçāo, diagnós. tico precoce e pronto tratamento adequado) e terciária (prevenção da invalidez, readaptação, reabilitação) que devem ser implantadas de forma integrada.

Esta questão que parece encerrar uma discussão estéril e acadêmica, na verdade, tem tido reflexos práticos de grande abrangência: na organização dos serviços, faz com que se criem dois organismos que mais se perturbarão, além de determinar desperdícios e recursos; no atendimento indi. vidual, conduz ao tratamento sintomático e à subestimação ou inexistência de procedimentos educativos; conduz à superestimação de consulta, da cirurgia e dos demais procedimentos assistenciais, resultando na desvalorização de procedimentos educativos, de vigilância sanitária e de vigilância epidemiológica. Proclamar a supremacia ou prioridade da profilaxia ou da terapêtica, leva ao atraso institucional da saúde.

d) As categorias sociais

A população brasileira pode ser dividida, grosso moCadernos de Saúde Pública, R.J., 3 (3): 315-331, jul/set, 1987 
do, em três conjuntos mais ou menos bem definidos: o primeiro, constituído por aqueles que têm melhor renda, a classe dominante - os proprietários de grandes áreas, grandes e médios empresários e comerciantes, prestadores de serviço de renda significativa, os executivos e outras pessoas bem-assalariadas - constitui uma fração que vai de 4 a $8 \%$ da população que pode arcar, integralmente, com as despesas com os serviços sanitários; o segundo, abrangendo de 30 a $65 \%$ da população, conforme a região considerada, composto pela parcela de assalariados mais ou menos organiza. da, desfruta dos serviços da previdência social, e o terceiro, composto pelos desempregados, pelos subempregados, pelo grande contingente de despossuídos, marginalizados das cidades médias, grandes e das metró poles e grande fração da população rural, é servida pela assistência pública. A primeira camada dispóe dos melhores cuidados e serviços de saúde, das instalações mais confortáveis, da tecnologia mais so. fisticada, de profissionais, extremamente, bem qualificados e dos serviços mais eficientes; a segunda é atendida pelos serviços próprios da previdência social, por profissionais e serviços contratados ou credenciados, remunerados por tarefa ou produção; a terceira é a tendida pelos serviços municipais e estaduais. $O$ que é interessante destacar, como fenômeno ideológico, é que cada um destes três tipos de serviços tem uma organização e uma dinâmica, inteiramente, diferente das demais. Um mesmo profissional, não importa se médico, dentista, porteiro, atendente, que milite em dois ou três deles, exercerá sua função profissional de forma, inteiramente, distinta em cada um. Porque se uma pessoa é pobre, remediada ou rica, isto, por si só, fará com que os demais a tratem diversamente; $\mathrm{e}$ se um profissional é funcionário do governo, prestador autônomo de serviço ou empregado de uma empresa, terá, necessariamente, um desempenho diverso, na dependência desta circunstância, além dasituação social do cliente.

Aqui se situa uma das encruzilhadas mais importantes das que separam e permitem identificar os quadros políticos mais conscientes, dentre os profissionais de saú de. E é aqui, um dos pontos mais importantes do processo educativo dos profissionais de saúde que deve ser objeto da melhor atenção do sistema de recursos humanos de uma secretaria de saúde de um governo democrático e popular.

e) Os serviços ativos e passivos

Diz-se que um serviço de saúde tem funcionamento passivo, qualquer que seja o seu grau de resolutividade e qualquer que seja o volume dos serviços que presta, quando, somente, atende àqueles que o procuram. Uma agência sani-

Cadernos de Saúde Pública, R.J., 3 (3): 315-331, jul/set, 1987 
tária é chamada de ativa, quando ela se dirige para sua população-alvo, buscando identificar as pessoas em risco, contribuindo para o desenvolvimento da educação, promovendo a vigilância sanitária na ârea sob sua responsabilidade, integrando-se com as demais agências de bemestar, visando à promoção da saúde e à profilaxia das enfermidades; enfim, quando seus procedimentos não ficam na dependência da iniciativa da clientela.

\section{f) A delimitação da responsabilidade}

A indefinição de responsabilidade e a desorganização dos serviços de saúde são, simultaneamente, reflexo de sua desimportância aos olhos do poder e ganho secundário com - qual esse poder pretende gratificar os profissionais, corrompendo-os para que se acumpliciem no jogo de fazer de conta, de que exercem ações de saú de. E tem conseguido es. te objetivo. Os profissionais de saúde se acumpliciam na medida em que tiram proveito da desorganização e da indefinição de responsabilidade, recusam os instrumentos de controle de qualidade dos serviços prestados e se colocam acima das exigências e necessidades da clientela. É preciso desfazer esta situação já cronificada, não só pela valorização do trabalho, mas pela simultânea definição, em cada serviço, da clientela sob sua responsabilidade e pela reorganização do setor, de modo a capacitá-lo a produzir aquilo que é seu ob. jetivo, serviços de saúde de boa qualidade.

A definição precisa da responsabilidade de cada categoria funcional e de cada serviço, somada à adoção de ins. trumentos de controle de qualidade do trabalho produzido, são medidas cujo significado deve ser discutido em cada instância do sistema com os funcionários, representantes da so. ciedade e de usuários.

\section{g) A questão da democracia}

O primeiro e mais importante momen to da in teração dos conceitos de saúde e democracia, a chamada DEMOCRATIZAÇÃO DA SAÚDE. consiste em se assegurar a todos o direto de acesso a serviços de saúde de boa qualidade, dever indeclinável do poder estatal, como contrapartida necessária do direito que tem cada cidadão de desfru tá-lo. $O$ exercício do governo popular e democrático obriga a utilização de todos os meios ao alcance para o cumprimento deste objetivo. É preciso que cada cidadão seja atendido com prontidão, presteza, cortesia e eficiência, quando tenha ameaçada ou comprometida sua saúde. Este é o primeiro e mais importante dos objetivos governamentais, no setor, e tudo mais deve se subordinar a ele. 
Em segundo lugar, deve-se considerar a questão da democratização de cada agência, em particular. Aqui, é preciso considerar, preliminarmente, a existência e influência do individualismo anarcóide ou anarquista, detestável praga política cultivada pela ditadura e fomentada pelo empobrecimento e perda da importância social das camadas médias e das chamadas profissões liberais. $O$ assembleísmo e o corporativismo são as expressões mais difundidas desta distorção ideológica. Outra, é a supervalorização das questões e problemas locais, com a conseqüente perda da perspectiva do processo político-administrativo global ou do sistema de saúde, enquanto totalidade. Acrescente-se a confusão que se faz entre os conceitos de autoridade e autoritarismo. Na ditadura, a au toridade governamental carecia de legitimidade, pois que, voltada para interesses que não eram os populares e originada de um golpe militar que pretendia se perenizar. Daí, seu caráter autoritário. Instalado o processo democrático, ao menos formal, a situação é outra. Portanto, é preciso iniciar o processo de discussão deste fenômeno e se iniciar a busca pela recuperação da respeitabilidade da autoridade pública.

\subsubsection{Fatores Político-administrativos}

Os fatores ideológicos resultam de fatos econômicos e ocasionam fatos políticos, mas existem alguns fatores que são, preponderantemente, políticos ou administrativos:

a) investimentos públicos imediatistas, visando ao retorno imediato e lucratividade contabilizável;

b) dissociação dos programas de bem-estar social, separação dos programas profiláticos dos assistenciais e dissociação de cada um destes, em atividades incomunicáveis;

c) desvalorização do serviço público civil da administração direta;

d) tal desvalorização foi muito mais sentida no setor de bem-estar social e, muito mais agudamente, na área da saúde, refletindo-se tanto no sucateamento dos serviços quanto no aviltamen to salarial dos profissionais;

e) adoção de uma política hospitalocêntrica e praticada através da compra de serviços que eram remunerados por uma moeda, especialmente, inventada, as "unidades de serviço", o que se transformou em fator de incontrolável cor. rupção e mau atendimento;

f) progressiva desvalorização das "unidades de serviço" fomentando e, até justifican do, as práticas corrompidas e a má qualidade dos serviços prestados, tornados cada vez piores;

g) pulverização dos recursos, divididos por incontáveis serviços; 
h) privilegiamento do poder federal no controle e na atribuição dos recursos tributários e previdenciários arrecadados;

i) injustiça da arrecadação previdenciária, que é a grande fonte de financiamento das ações de saúde, alcançando vinte por cento da massa dos salários, quando deveria incidir sobre o faturamento, o capital e o lucro;

j) política tecnocratizada de recursos humanos, desvinculada das exigências dos serviços e das necessidades sociais, além da marginalizada em relação ao sistema formal de instrução;

1) política de medicamentos voltada para privilegiar os grupos empresariais internacionais e reforçadora da dependência tecnológica;

m) aban dono dos programas de vigilância sanitária;

n) subordinação do poder municipal ao estadual e deste, ao federal;

o) excessiva centralização;

p) desorganização;

q) indefinição de responsabilidade;

r) supervalorização dos proce dimentos curativos, hospitalares e que empregam tecnologia dispendiosa e estrangeira;

s) seleção e promoção de pessoal dirigidas para o atendimento de compromissos eleitorais e para o favorecimento de grupos;

t) corrup̧̧ão.

\section{PRINCÍPIOS FUNDAMENTAIS DA POLITICA SANITÁRIA}

Existe, hoje, uma concordância muito grande sobre alguns pontos fundamentais de uma política sanitária progressista e que tem valor de princípios norteadores da ação. Tais princípios são:

\section{A SAUUDE COMO PRÁTICA DEMOCRÁTICA}

As questões mais significativas com respeito a este tema, já foram enunciadas anteriormente. Mas implica em se assegurar, a todos, o direito a condiçōes mínimas de salubridade e às melhores e mais competentes condições de assistência; ademais, implica na democratização dos serviços, pela participação em sua gestão de conselhos comunitários, com a participação dos servidores.

\section{O PRINCIPIO DA RESPONSABILIDADE}

Em primeiro lugar, na responsabilidade do poder esta- 
tal de garantir, a todos, as melhores condições possíveis de saúde e assistência. $\mathrm{Na}$ responsabilidade que têm os serviços de saúde, em particular, com a salubridade do meio e as condiçōes de assistência a serviço da população, que lhe é atribuída.

\section{REGIONALIZAÇÃO E SETORIZAÇÃO}

Somente será possível se assegurar o exercício do princípio da responsabilidade, quando cada unidade sanitária ou outra agência de saúde tiver, perfeitamente, definida a população abrangida em sua jurisdição. A situação atual, quando todos os serviços são responsáveis por toda a população, resulta em que ninguém é responsável. É in dispensável que cada município seja organizado em distritos sanitários e estes, em setores que alcancem dois a quatro mil habitantes mais ou menos, sendo que os distritos não devem abranger população maior que sessenta e setenta mil pessoas.

\section{PREVENÇÃO E ASSISTÊNCIA COMO CATEGORIAS INSEPARÁVEIS}

Impõe a unificação, em um sistema único, de todos os programas de prevenção e de assistência à saúde. Hoje, não é possível mais admitir que diversas agências municipais, numerosos serviços estaduais e vários ministérios (somente no nível oficial) ex ecutem programas de saúde, de forma desorganizada, e em desfavorecimento da população.

\section{PROGRAMAÇÃO ATIVA}

Os serviços de saúde devem funcionar regidos pela necessidade de manter atividades ex tramuro, voltadas para evitar as enfermidades e, quando ão for possivel, diagnosticar e tratar o mais rapidamente possível. Cada unidade sanitária deve manter, em ação compartilhada com a comunidade, programas de vigilância sanitária que ultrapassem a vigilân. cia de alimentos, medicamentos, cosméticos e produtos domissaneantes e alcancem a proteção e recuperação do ambiente físico, das condições de moradia e de transporte, das condições de trabalho, de serviços urbanos e de segurança individual e coletiva.

\section{O PRINCÍPIO DA HIERARQUIZAÇÃO}

Presume uma organização de serviços, de crescente complexidade, em função de sua sofisticação e capacidade resolutiva, desde as unidades mais elementares do ponto de 
vista de dotação de pessoal e de recursos tecnológicos, as mais sofisticadas, que serão as referências distritais, $m$ cipais, regionais, estaduais ou federais. A unidade eleme de saúde, abrangendo uma localidade de moradia ou de balho, será a única instância a poder encaminhar o cli ou o problema de saúde ao nível superior que tiver qu mobilizado.

\section{PRINCIPIO DA EQÜIDADE}

O objetivo geral é garantir a todos, em condiçōe igualdade de oportunidade, o melhor tratamen to possive

As prioridades devem ser estabelecidas pela limit: dos recursos, mas deverão ser determinadas por exigên clínicas, epidemiológicas ou pela necessidade social.

\section{PRINCÍPIO DA DESCENTRALIZAÇÃO}

É fundamental que se promova, ao máximo, a des tralização administrativa, de modo que as agências regio e as unidades sanitárias distritais sejam dotadas de capac de para gerir recursos humanos, materiais e fin anceiros.

No entanto, é preciso que haja uma supervisão pe: nente do nível central para as regionais e destas, para as dades distritais e locais.

A supervisão deve ser integrada, educativa e capa avaliar os serviços e encaminhar propostas de melhori: desempenho e rendimento, em termos de quantidade, o tunidade e qualidade do serviço prestado.

\section{PRINCÍPIO DA INTEGRAÇÃO}

Todos os programas de saúde tèm que funcionar $i$ grados em una mesma área de jurisdição e no mesmo n de atuação.

Em princípio, deve-se promover um esforço para i grar todas as atividades sanitárias do setor público e de com o privado.

Para isto, é necessário fortalecer e prestigiar os 0 nismos de gestão ativa, Comissão Interinstitucional de : de (CIS) no âmbito estadual; Comissões Regionais In te titucionais de Saúde (CRIS), nas regiões de saúde e Co sões Interinstitucionais Municipais de Saúde ou Comis Locais Interinstitucionais de Saúde (CIMS ou CLIS), municípios.

A par disto, deve se ativar o Conselho Estadua Saúde, como órgão consultivo e com algumas atribui normativas, constituído com um máximo de representa dade das categorias profissionais de saúde, de prestadore

Cadernos de Saúde Pública, R.J., 3 (3): 315-331, jul/se t, 1 
serviços, de usuários, partidos políticos e agências do serviço público que tenham atuação na área de saúde.

\section{PRINCIPIO DA CONTINUIDADE}

É necessário e desejável que todo programa ou atividade programada vise à continuidade. É preciso que o planejamento das ações se faça prevendo, ao máximo, a persistência temporal do projeto.

Programas de emergência podem e devem ser estabelecidos, para atender a exigências imprevistas (catástrofes naturais ou provocadas, por exemplo); previstas (migraçðes trabalho sazonal, festivais, exposiçðes); ou por interesse da política sanitária (mutirões, atenção por unidades móveis). Estas últimas, no entanto, devem ser entendidas como ação de emergência e visarem, no futuro, o mais próximo possível, sua instalação como atividade permanente. 